\title{
A randomized double blind placebo controlled clinical trial of N-Acetylcysteine added to risperidone for treating autistic disorders
}

\author{
Ahmad Ghanizadeh ${ }^{1,2^{*}}$ and Ebrahim Moghimi-Sarani ${ }^{2}$
}

\begin{abstract}
Background: This study examined the efficacy and safety of N-acetylcysteine (NAC) augmentation for treating irritability in children and adolescents with autism spectrum disorders (ASD).

Method: Forty children and adolescents met diagnostic criteria for ASD according to DSM-IV. They were randomly allocated into one of the two groups of NAC (1200 mg/day)+risperidone or placebo+risperidone. NAC and placebo were administered in the form of effervescent and in two divided doses for 8 weeks. Irritability subscale score of Aberrant Behavior Checklist $(A B C)$ was considered as the main outcome measure. Adverse effects were also checked.

Results: The mean score of irritability in the NAC+risperidone and placebo+risperidone groups at baseline was 13.2(5.3) and 16.7(7.8), respectively. The scores after 8 weeks were 9.7(4.1) and 15.1(7.8), respectively. Repeated measures of ANOVA showed that there was a significant difference between the two groups after 8 weeks. The most common adverse effects in the NAC+risperidone group were constipation (16.1\%), increased appetite (16.1\%), fatigue (12.9\%), nervousness (12.9\%), and daytime drowsiness (12.9\%). There was no fatal adverse effect.

Conclusions: Risperidone plus NAC more than risperidone plus placebo decreased irritability in children and adolescents with ASD. Meanwhile, it did not change the core symptoms of autism. Adverse effects were not common and NAC was generally tolerated well.
\end{abstract}

Trial registration: This trial was registered at http://www.irct.ir. The registration number of this trial was IRCT201106103930N6

Keyword: Autism, Clinical trial, Randomized, Therapy, N-acetylcysteine, Oxidative stress

\section{Background}

Autism spectrum disorders (ASD) are characterized by the three main symptoms of: a) significant impairments in social relationships, b) language and communication deficits, and c) restricted interests. Although, autistic disorders are not very common, their current rates are higher than that of the previously reported rates [1]. About $1.9 \%$ of school aged children obtain screening cutoff score for probable autistic disorder [2]. The rate for typical autism

\footnotetext{
* Correspondence: ghanizad@sina.tums.ac.ir

'Research Center for Psychiatry and Behavioral Sciences, Shiraz University of Medical Sciences, School of Medicine, Shiraz, Iran

${ }^{2}$ Department of Psychiatry, Shiraz University of Medical Sciences, School of Medicine, Shiraz, Iran
}

in five-year-old children is 6.26 per 10,000 [3]. In addition, the global prevalence of autism spectrum disorders is $62 / 10000[4]$.

The neurobiology and etiology of autism are not clearly known [5]. However, genetic [6], neurologic, metabolic, and immunologic factors are suggested to be involved. It is proposed that there is an imbalance of oxidative stress and anti-oxidative defenses in children with autism $[7,8]$. The deficit in antioxidant system is specific in autism [9] and it mediates the association of some behavioral symptoms and immunity function [10]. While plasma antioxidant capacity is decreased [11], the plasma oxidative stress indicators, such as nitric oxide (NO) and malondialdehyde (MDA), are increased [12]. In addition, lipid peroxidation is increased in autism [13]. Oxidative stress markers in 
urine may represent oxidative stress index in autistic patients and some of them are suggested as the biomarkers of autism [14]. The levels of superoxide dismutase (SOD) and glutathione peroxidase, as antioxidant enzymes, are lower in autism than that of the controls [15].

Oxidative stress negatively affects mitochondrion through respiratory chain [16]. Therefore, oxidative stress is suggested as a target for treating autism [7,17]. In addition, animal models of autism revealed that targeting oxidative markers was effective for treating autism [18].

Glutathione plays a significant role in defense against oxidative stress in autism $[7,19]$. The level of glutathione in the cerebellum and temporal cortex of patients with autism are markedly decreased $(34.2 \%$ and $44.6 \%$, respectively) [20]. The levels of both reduced glutathione and total glutathione are lowered in autistic patients than that of the controls [21]. Moreover, glutathione pathway gene variation increases the risk of autistic disorders [22].

Glutathione, which is the most important intracellular defense against oxidative stress, consists of glutamate, glycine, and cysteine [7]. The pathways of methionine cycle, transsulfuration pathway, and GSH-synthesis pathway produce glutathione [23]. The role of cysteine for the production of glutathione is very important because cysteine has a rate-limiting role [7]. Recently, an eight-week, open-label trial showed that glutathione supplementation increased the reduced-form of glutathione in plasma in children with autism spectrum disorders [24]. This supplementation also increased the plasma levels of sulfate, cysteine, and taurine [24].

In addition, glutamate is involved in the pathophysiology of autism [25] and glutamate blockers improve the animal models of autism [26,27]. Some other interventions targeting glutamate are suggested for treating autism as well [28-30].

$\mathrm{N}$-acetylcysteine (NAC) is an antioxidant precursor to glutathione [31]. NAC restores GSH level [31]. In addition, NAC scavenges oxidants such as hydroxyl radical and $\mathrm{H}_{2} \mathrm{O}_{2}$ [32]. NAC improves glutamate homeostasis and decreases the relapse rate in drug-dependent patients [33]. NAC is an effective and safe agent for treating schizophrenia [34], bipolar disorder [35], Alzheimer's disease [36], and nail biting [37]. Moreover, the adverse effects of NAC are mild and self-limited in children [38]. NAC is an over-thecounter supplement.

About $75.5 \%$ of patients with autism respond to risperidone while the rate for placebo is $11.5 \%$ (effect size $=1.2$ ) [39]. Aripiprazole with the effect size of 0.87 is effective too [40]. This trial investigates the efficacy and safety of NAC as an adjuvant treatment with risperidone for treating the irritability of children with ASD. Considering the role of glutathione in autism and the effect of NAC on glutathione level, it is hypothesized that NAC as an augmentation agent decreases irritability score in children with ASD.

\section{Methods}

This study was an eight week randomized double-blind placebo-controlled clinical trial with two parallel groups. The patients, parents, and independent assessor were blind to the allocation of patients. The patients were randomly allocated into one of the two groups using a random number generator.

The participants were a convenient sample of outpatients children aged between 3.5 to 16 years old from both genders. The sample was recruited from the Child and Adolescent Psychiatriy Clinics affiliated with Shiraz University of Medical Sciences, Iran.

The diagnosis of autism was made using DSM-IV-TR criteria. The diagnosis was in accordance with Autism Diagnostic Interview-Revised (ADI-R) [41]. All the interviews were conducted by an expert child and adolescent psychiatrist (A.G.). Assessments were performed by a resident of psychiatry trained to use the questionnaire and checklist. The level of intelligence was not considered as an exclusion criterion. However, the participants should be able to take the medications.

The patients were free from any concomitant medication. Otherwise, the dose of medication should not be markedly changed during two weeks prior entering into this study. The dose of concomitant medication was not markedly changed during this trial.

Patients with psychotic disorders, active substance abuse or dependence, unstable medical condition, evidence of active liver disease, seizure disorder, unstable hypertension or cardiac disease, unstable asthma, and kidney disease as determined by the investigator were not included. Taking concomitant medications with glutamatergic effects (e.g., dextromethorphan, D-cycloserine, amantadine, memantine, lamotrigine, riluzole) was not allowed. In addition, those with hypersensitivity/allergy to NAC were not included.

One of the two groups received risperidone plus $\mathrm{N}$-Acetylcysteine (1200 mg/day). The patients received $1200 \mathrm{mg} /$ day NAC in two divided doses. Both NAC and placebo tablets were administered in the form of effervescent. The other group received risperidone plus placebo tablets. The shape, size, taste, and color of NAC and placebo were identical.

The dose was titrated up during two weeks. The dose was not fixed. In addition, all the patients in both groups received risperidone. Risperidone started at the dose of $0.5 \mathrm{mg} /$ day and it was titrated up to $2 \mathrm{mg} /$ day during three weeks for children less than $30 \mathrm{~kg}$. The dose for children more than $30 \mathrm{~kg}$ was up to $3 \mathrm{mg} /$ day $[42,43]$. The dose of risperidone was not fixed and it could be changed considering the clinical symptoms and adverse effects. 
The primary outcome measure was Aberrant Behavior Checklist [44]. ABC consists of 58 items and includes 5 subscales. The subscales are Irritability, Lethargy and Social Withdrawal, Stereotypic Behavior, Hyperactivity and Noncompliance, and Inappropriate Speech.

The changes of Irritability subscale score was considered as the main outcome of the current trial.

It was completed at pre-intervention, 4 weeks after the beginning of intervention, and 8 weeks after the beginning of intervention. In addition, the adverse effects and extrapyramidal symptoms were systematically examined and assessed using checklists [43]. The patients and their parents were also asked regarding possible adverse effects.

This trial's protocol and procedures were approved by Ethics Committee of Shiraz University of Medical Sciences, Iran. Then, this trial was registered at http://www.irct.ir. The registration number of this trial was IRCT201106103930N6. This trial was performed in 2011 and 2012. The parents of children provided written informed consent.

\section{Analysis}

SPSS was used to perform statistical analyses. Chi-Square test was used to compare the gender ratio between the two groups. The mean of age was compared between the two groups using independent t-test. Repeated Measures of ANOVA was used to examine the effect of interventions on the subscales scores of $\mathrm{ABC}$. Intent-to-Treat (ITT) using Last Observed Carried Forward (LOCF) with at least one post-treatment evaluation was used to handle missing data [45]. The Cohen's d was calculated to measure effect size. P value less than 0.05 was set for being statistically significant. This is an exploratory small sample size trial.

\section{Results}

Out of 47 children who were screened, 40 patients were randomized into one of two groups. The reasons for the drop of patients in the two groups are displayed in Figure 1. The number of boys in the NAC and placebo

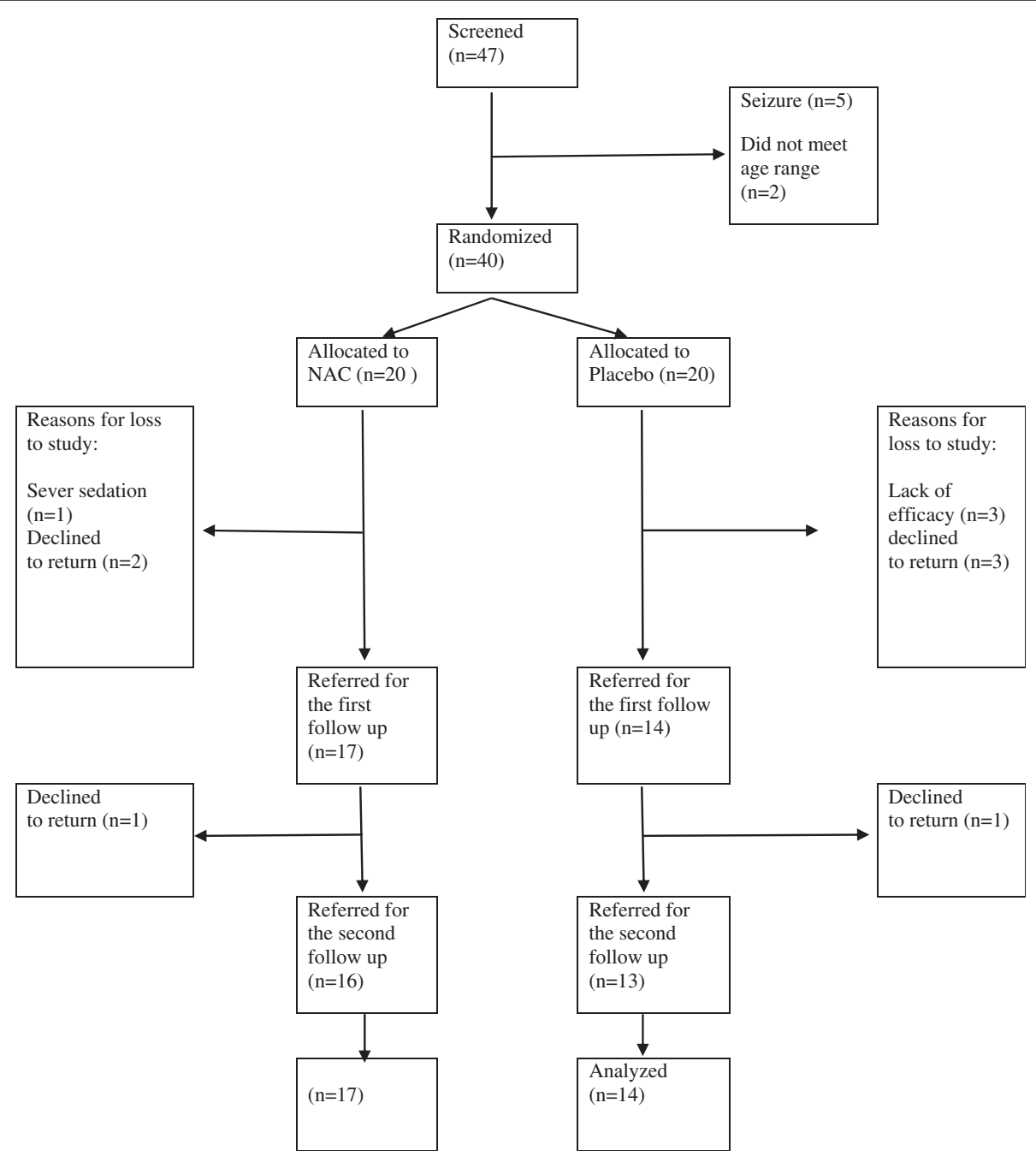

Figure 1 Flow chart for the clinical trial N-Acetylcysteine + risperidone versus Placebo+risperidone. 
groups was 13 and 12, respectively. There was no statistically significant difference between the two groups regarding gender ratio $(\mathrm{X} 2=.4, \mathrm{df}=1, \mathrm{P}=0.5)$. In addition, the mean of age was not different between the two groups $(\mathrm{t}=0.4, \mathrm{df}=29, \mathrm{P}=0.4)$. The mean age of children in the NAC and placebo group was 8.8(3.1) and 7.9(2.4) years, respectively. The list of concomitant medications is presented in Table 1. The mean (SD) dose of risperidone in the $\mathrm{NAC}+$ risperidone and placebo+risperidone groups was $0.76(0.2) \mathrm{mg} /$ day and $0.92(0.3) \mathrm{mg} / \mathrm{day}$, respectively. It was not significantly different between the two groups $(\mathrm{t}=1.4, \mathrm{df}=29, \mathrm{P}=0.1)$.

Repeated measures ANOVA showed both NAC and Placebo decreased Irritability subscale score during the trial $(\mathrm{F} 1.4,43.0=10.5, \mathrm{P}<0.001)$ (Figure 2). The irritability scale score decreased from 13.2(5.3) to 9.7(4.1) in the NAC+risperidone group. However, the irritability score decreased $16.7(7.8)$ to 15.1 (7.8) in the placebo+risperidone group. Repeated measures ANOVA showed that the effects of groups were significantly different $(F 1,29=4.9$, $\mathrm{P}<0.035)$. Moreover, the interactive effect of time and group (timexgroup) was not statistically different (Table 2). The pattern of changes for Irritability subscale score was different between the NAC+risperidone and placebo+ risperidone groups. NAC+risperidone more than placebo+ risperidone decreased this score (effect size $=.14$ ). There was no difference between the two groups regarding Lethargy and Social Withdrawal, Stereotypic Behavior, Hyperactivity and Noncompliance, and Inappropriate Speech subscales scores.

\section{Adverse effects}

Adverse effects were also checked. None of the participants experienced any fatal adverse effect. Only one patient withdrew due to adverse effect in the NAC group. The adverse effects were usually mild. The most common adverse effects were constipation (16.1\%), increased appetite (16.1\%),

$\begin{aligned} & \text { Table } \mathbf{1} \text { The number of patients taking concomitant } \\
& \text { medications during this trial }\end{aligned}$
\begin{tabular}{lll}
\hline $\begin{array}{l}\text { Medication } \\
\text { (Mean dose) }\end{array}$ & $\begin{array}{l}\text { N-Acetylcysteine+risperidone } \\
\text { group (Number) }\end{array}$ & $\begin{array}{l}\text { Placebo+risperidone } \\
\text { group (Number) }\end{array}$ \\
\hline $\begin{array}{l}\text { Clonidine } \\
(0.75 \mathrm{mg} / \text { day) }\end{array}$ & 5 & 3 \\
$\begin{array}{l}\text { Folic acid } \\
(1 \mathrm{mg} / \text { day })\end{array}$ & 2 & 0 \\
$\begin{array}{l}\text { Imipramine } \\
(10 \mathrm{mg} / \text { day })\end{array}$ & 1 & 0 \\
$\begin{array}{l}\text { Biperiden } \\
(2 \mathrm{mg} / \text { day })\end{array}$ & 1 & 1 \\
$\begin{array}{l}\text { Nortriptyline } \\
(12.5 \mathrm{mg} / \text { day })\end{array}$ & 1 & 0 \\
$\begin{array}{l}\text { Topiramate } \\
(12.5 \mathrm{mg} / \text { day) }\end{array}$ & 0 & 2 \\
\hline
\end{tabular}

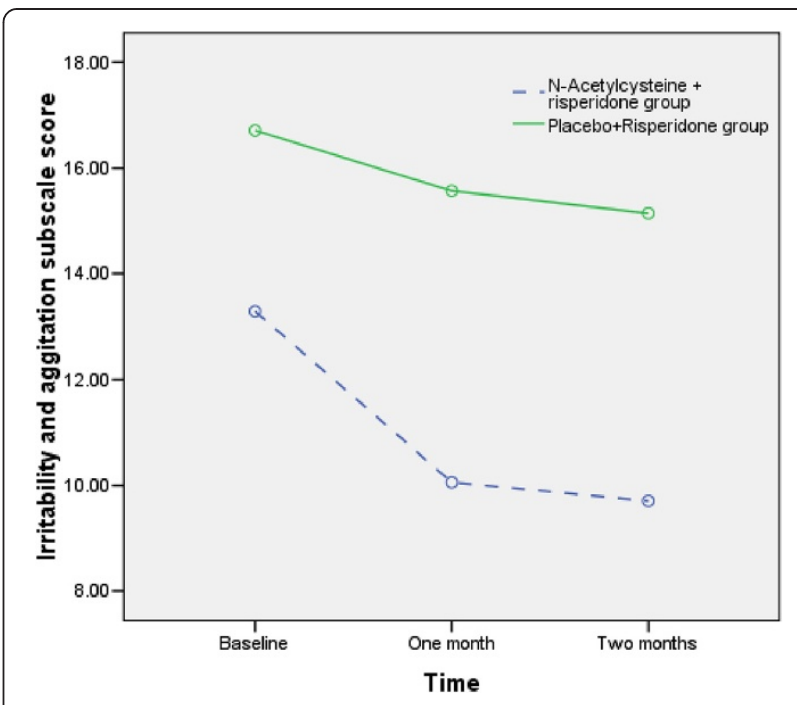

Figure 2 Comparison of irritability subscale scores between $\mathrm{N}$-Acetylcysteine + risperidone group and Placebo+Risperidone group.

fatigue $(12.9 \%)$, nervousness (12.9\%), and daytime drowsiness $(12.9 \%)$ (Table 3$)$.

\section{Discussion}

This randomized double-blind placebo-controlled clinical trial showed that NAC as an adjuvant therapy more than placebo decreased Irritability score in children with ASD. This result suggests that oral NAC as a supplement may be used in order to decrease the level of irritability in children with autistic disorders. Considering the low level of glutathione in autism [7], it is possible that NAC may increase the production of glutathione and enhance anti-oxidative stress system. Our results are in similar line to a recently published case report [46] and a pilot trial showed that NAC more than placebo decreased irritability in children with autism [47]. In addition, our results are very similar to a previously published study reported that NAC was tolerated well and there was no serious adverse effect [47]. The study by Hardan et al., is the only study reported that oral NAC is effective for treating autism [47]. Their participants were taking constant concomitant psychotropic medications and behavioral interventions. However, the type and dosage of the psychotropic medications were not reported. The most common adverse effects of the previous study were constipation, nausea, and diarrhea [47].

\section{Limitation and future direction}

The sample size was small and the duration of current trial was very short. It is not clear whether the symptom will relapse after the discontinuation of NAC. In addition, it is not examined whether this effect will be stable in long term. Further studies may investigate whether NAC enhances anti-oxidative stress system or NAC decreases 
Table 2 The mean (standard deviation) scores of ABC subscales in the N-Acetylcysteine + risperidone group and Placebo+risperidone group

\begin{tabular}{|c|c|c|c|c|c|}
\hline Subscale & Group & $\begin{array}{l}\text { Baseline } \\
\text { score }\end{array}$ & $\begin{array}{l}\text { One month after the } \\
\text { onset of intervention }\end{array}$ & $\begin{array}{l}\text { Two months after the } \\
\text { onset of intervention }\end{array}$ & $\begin{array}{l}\text { Between groups } \\
\text { difference }\end{array}$ \\
\hline \multirow[t]{2}{*}{ Irritability } & N-Acetylcysteine + risperidone & $13.2(5.3)$ & $10.0(4.1)$ & $9.7(4.1)$ & \multirow[t]{2}{*}{$F 1,29=4.9, P<0.035$} \\
\hline & Placebo+Risperidone & $16.7(7.8)$ & 15.5(7.9) & 15.1(7.8) & \\
\hline \multirow[t]{2}{*}{ Hyperactivity and Noncompliance } & $\mathrm{N}$-Acetylcysteine + risperidone & $29.3(6.4)$ & $21.4(7.7)$ & 18.3(6.9) & \multirow[t]{2}{*}{$F 1,29=2.4, P=0.12$} \\
\hline & Placebo+Risperidone & $31.9(8.9)$ & 26.8(11.0) & $24.3(12.1)$ & \\
\hline \multirow[t]{2}{*}{ Lethargy and Social Withdrawal } & N-Acetylcysteine + risperidone & $11.9(6.5)$ & $9.0(5.7)$ & $8.5(6.5)$ & \multirow[t]{2}{*}{$F 1,28=0.4, P=0.53$} \\
\hline & Placebo+Risperidone & $12.2(8.3)$ & $11.0(7.8)$ & $10.9(7.5) 6$ & \\
\hline \multirow[t]{2}{*}{ Stereotypic Behavior } & N-Acetylcysteine + risperidone & $6.6(4.5)$ & 4.5(3.6) & $3.9(2.7)$ & \multirow[t]{2}{*}{$F 1,28=2.8, P=0.1$} \\
\hline & Placebo+Risperidone & $8.5(6.3)$ & $7.7(6.2)$ & $7.8(6.6)$ & \\
\hline \multirow[t]{2}{*}{ Inappropriate Speech } & $\mathrm{N}$-Acetylcysteine + risperidone & $3.9(3.7)$ & 3.8(3.7) & $3.2(3.4)$ & \multirow[t]{2}{*}{$F 1,29=1.8, P=0.1$} \\
\hline & Placebo+Risperidone & $5.7(3.8)$ & $5.3(3.7)$ & $5.2(4.0)$ & \\
\hline
\end{tabular}

Table 3 The number of patients with the adverse effects in the $\mathrm{N}$-Acetylcysteine + risperidone group and Placebo+risperidone group

\begin{tabular}{|c|c|c|c|c|}
\hline \multirow[t]{2}{*}{ Adverse effect } & \multicolumn{2}{|c|}{$\mathrm{N}$-Acetylcysteine + risperidone group } & \multicolumn{2}{|c|}{ Placebo+risperidone group } \\
\hline & Number & Percent & Number & Percent \\
\hline Daytime drowsiness & 4 & 12.9 & 2 & 6.5 \\
\hline Morning drowsiness & 1 & 3.2 & 0 & 0 \\
\hline Stiffness & 2 & 6.5 & 0 & 0 \\
\hline Slowed movement & 2 & 6.5 & 0 & 0 \\
\hline Decreased Appetite & 1 & 3.2 & - & 0 \\
\hline Fatigue & 4 & 12.9 & 4 & 3.2 \\
\hline Constipation & 5 & 16.1 & 1 & 3.2 \\
\hline Increased appetite & 5 & 16.1 & 3 & 9.7 \\
\hline Decreased appetite & 2 & 6.5 & 1 & 3.2 \\
\hline Diarrhea & 0 & 0 & 1 & 3.2 \\
\hline Tremor & 2 & 6.5 & 0 & 0 \\
\hline Abdominal pain & 1 & 3.2 & 0 & 0 \\
\hline Nervousness & 4 & 12.9 & 0 & 0 \\
\hline Itches & 1 & 3.2 & 1 & 3.2 \\
\hline Restlessness & 2 & 6.5 & 2 & 6.5 \\
\hline Twitches & 1 & 3.2 & 0 & 0 \\
\hline Blurred vision & 1 & 3.2 & 0 & 0 \\
\hline Urinary retention & 0 & 0 & 0 & 0 \\
\hline Dizziness & 0 & 0 & 0 & 0 \\
\hline Skin rash & 0 & 0 & 0 & 0 \\
\hline Itches & 0 & 0 & 0 & 0 \\
\hline Dry mouth & 0 & 0 & 0 & 0 \\
\hline Swallowing difficulty & 0 & 0 & 0 & 0 \\
\hline Seizure & 0 & 0 & 0 & 0 \\
\hline
\end{tabular}


hyperglutaminergic state in ASD. In order to have a more homogenous group, further studies should not include a wide range of children. In addition, it is recommended to assess the quality of life using other secondary measures in further studies. Finally, the concomitant use of risperidone may limit the efficacy of obtained results. Therefore, the efficacy of higher doses of NAC should be investigated in further trials.

\section{Conclusion}

NAC+risperidone decreased irritability in this trial. This improvement in the NAC+risperidone group was more than that of the placebo+risperidone group. However, $\mathrm{NAC}$ no more than placebo decreased other $\mathrm{ABC}$ subscales scores including: Lethargy and Social Withdrawal, Stereotypic Behavior, Hyperactivity and Noncompliance, and Inappropriate Speech. Future trials with larger sample sizes, longer durations, and higher doses are required in order to examine the possible effects of NAC on autism.

\section{Competing interests}

The authors declare that they have no competing interests.

\section{Authors' contributions}

AG was responsible for the initial conception and drafting of the manuscript. AG and EM gathered the data and revised the preliminary draft of the manuscript. Both authors read and approved the final manuscript.

\section{Acknowledgments}

This study was the thesis of Dr. Ebrahim Moghimi-Sarani. This study was supported by a grant from Shiraz University of Medical Sciences (Grant No: 5545) to Prof. Ahmad Ghanizadeh. The authors thank the participants and Dr. Shafian for her invaluable helps. We also thank Professor Soliman Mohammadi Samani from the Department of Pharmaceutics and the Department of Pharmaceutical Biotechnology at Shiraz University of Medical sciences for providing the placebo tablets.

Received: 11 March 2013 Accepted: 24 July 2013

Published: 25 July 2013

\section{References}

1. Kocovska E, Biskupsto R, Carina Gillberg I, Ellefsen A, Kampmann H, Stora T, Billstedt E, Gillberg C: The Rising Prevalence of Autism: A Prospective Longitudinal Study in the Faroe Islands. J Autism Dev Disord 2012, 42(9):1959-1966

2. Ghanizadeh A: A preliminary study on screening prevalence of pervasive developmental disorder in schoolchildren in Iran. J Autism Dev Disord 2008, 38(4):759-763.

3. Samadi SA, Mahmoodizadeh A, McConkey R: A national study of the prevalence of autism among five-year-old children in Iran. Autism 2012, 16(1):5-14.

4. Elsabbagh M, Divan G, Koh YJ, Kim YS, Kauchali S, Marcin C, Montiel-Nava C, Patel V, Paula CS, Wang C, et al: Global prevalence of autism and other pervasive developmental disorders. Autism research: official journal of the International Society for Autism Research 2012, 5(3):160-179.

5. Pardo CA, Eberhart CG: The neurobiology of autism. Brain Pathol 2007, 17(4):434-447

6. State MW, Levitt $P$ : The conundrums of understanding genetic risks for autism spectrum disorders. Nat Neurosci 2011, 14(12):1499-1506.

7. Ghanizadeh A, Akhondzadeh S, Hormozi, Makarem A, Abotorabi M, Firoozabadi A: Glutathione-related Factors and Oxidative Stress in Autism, a Review. Curr Med Chem 2012, 19(23):4000-4005.

8. Leoncini S, De Felice C, Signorini C, Pecorelli A, Durand T, Valacchi G, Ciccoli L, Hayek J: Oxidative stress in Rett syndrome: natural history, genotype, and variants. Redox Rep 2011, 16(4):145-153.
9. Melnyk S, Fuchs GJ, Schulz E, Lopez M, Kahler SG, Fussell JJ, Bellando J, Pavliv O, Rose S, Seidel L, et al: Metabolic imbalance associated with methylation dysregulation and oxidative damage in children with autism. J Autism Dev Disord 2012, 42(3):367-377.

10. Ghanizadeh A: Oxidative stress may mediate association of stereotypy and immunity in autism, a novel explanation with clinical and research implications. J Neuroimmunol 2011, 232(1-2):194-195.

11. Parellada M, Moreno C, Mac-Dowell K, Leza JC, Giraldez M, Bailon C, Castro C, Miranda-Azpiazu P, Fraguas D, Arango C: Plasma antioxidant capacity is reduced in Asperger syndrome. J Psychiatr Res 2012, 46(3):394-401.

12. Essa MM, Guillemin GJ, Waly MI, Al-Sharbati MM, Al-Farsi YM, Hakkim FL, Ali A, Al-Shafaee MS: Increased markers of oxidative stress in autistic children of the sultanate of oman. Biol Trace Elem Res 2012, 147(1-3):25-27.

13. Ming X, Stein TP, Brimacombe M, Johnson WG, Lambert GH, Wagner GC: Increased excretion of a lipid peroxidation biomarker in autism. Prostaglandins Leukot Essent Fatty Acids 2005, 73(5):379-384.

14. Damodaran $L P$, Arumugam G: Urinary oxidative stress markers in children with autism. Redox Rep 2011, 16(5):216-222.

15. Meguid NA, Dardir AA, Abdel-Raouf ER, Hashish A: Evaluation of oxidative stress in autism: defective antioxidant enzymes and increased lipid peroxidation. Biol Trace Elem Res 2011, 143(1):58-65.

16. Ghanizadeh A: Targeting Mitochondria by Olesoxime or Complement 1q Binding Protein as a Novel Management for Autism: A Hypothesis. Molecular Syndromology 2011, 2:50-52.

17. Ghanizadeh A, Berk M, Farrashbandi H, Alavi Shoushtari A, Villagonzalo KA: Targeting the mitochondrial electron transport chain in autism, a systematic review and synthesis of a novel therapeutic approach. Mitochondrion 2012, 2012. doi:10.1016/j.mito.2012.10.001.

18. Banji D, Banji OJ, Abbagoni S, Hayath MS, Kambam S, Chiluka VL: Amelioration of behavioral aberrations and oxidative markers by green tea extract in valproate induced autism in animals. Brain Res 2011, 1410:141-151.

19. Frustaci A, Neri M, Cesario A, Adams JB, Domenici E, Dalla Bernardina B, Bonassi S: Oxidative stress-related biomarkers in autism: Systematic review and meta-analyses. Free Radic Biol Med 2012, 52(10):2128-2141.

20. Chauhan A, Audhya T, Chauhan V: Brain Region-Specific Glutathione Redox Imbalance in Autism. Neurochem Res 2012, 37(8):1681-1689.

21. Al-Yafee YA, Al-Ayadhi LY, Haq SH, El-Ansary AK: Novel metabolic biomarkers related to sulfur-dependent detoxification pathways in autistic patients of Saudi Arabia. BMC Neurol 2011, 11:139.

22. Bowers K, Li Q, Bressler J, Avramopoulos D, Newschaffer C, Fallin MD: Glutathione pathway gene variation and risk of autism spectrum disorders. J Neurodev Disord 2011, 3(2):132-143.

23. Vitvitsky V, Thomas M, Ghorpade A, Gendelman HE, Banerjee R: A functional transsulfuration pathway in the brain links to glutathione homeostasis. J Biol Chem 2006, 281(47):35785-35793.

24. Kern J, Geier D, Adams J, Garver C, Audhya T, Geier M: A clinical trial of glutathione supplementation in autism spectrum disorders. Med Sci Monit 2011, 17(12):682.

25. Ghanizadeh A: Could fever and neuroinflammation play a role in the neurobiology of autism? A subject worthy of more research. Int J Hyperthermia 2011, 27(7):737-738.

26. Harrison C: Neurodevelopmental disorders: Glutamate blockers show benefit in models of autism spectrum disorders. Nat Rev Drug Discov 2012, 11(6):440-441.

27. Niederhofer $\mathrm{H}$ : Glutamate antagonists seem to be slightly effective in psychopharmacologic treatment of autism. J Clin Psychopharmacol 2007, 27(3):317-318.

28. Ghanizadeh A: c-Kit+ cells transplantation as a new treatment for autism, a novel hypothesis with important research and clinical implication. J Autism Dev Disord 2011, 41(11):1591-1592.

29. Ghanizadeh A: Methionine sulfoximine may improve inflammation in autism, a novel hypothesized treatment for autism. Arch Med Res 2010, 41(8):651-652.

30. Ghanizadeh A: Targeting of glycine site on NMDA receptor as a possible new strategy for autism treatment. Neurochem Res 2011, 36(5):922-923.

31. Dean $\mathrm{O}$, Giorlando F, Berk M: N-acetylcysteine in psychiatry: current therapeutic evidence and potential mechanisms of action. J Psychiatry Neurosci 2011, 36(2):78-86.

32. Aruoma Ol, Halliwell B, Hoey BM, Butler J: The antioxidant action of $\mathrm{N}$-acetylcysteine: its reaction with hydrogen peroxide, hydroxyl radical, superoxide, and hypochlorous acid. Free Radic Biol Med 1989, 6(6):593-597. 
33. Schmaal L, Veltman DJ, Nederveen A, van den Brink W, Goudriaan AE: $\mathrm{N}$-Acetylcysteine Normalizes Glutamate Levels in Cocaine-Dependent Patients: A Randomized Crossover Magnetic Resonance Spectroscopy Study. Neuropsychopharmacology 2012, 37(9):2143-2152.

34. Berk M, Copolov D, Dean O, Lu K, Jeavons S, Schapkaitz I, Anderson-Hunt M, Judd F, Katz F, Katz P: N-acetyl cysteine as a glutathione precursor for schizophreniaâ $E^{\prime \prime}$ double-blind, randomized, placebo-controlled trial. Biol Psychiatry 2008, 64(5):361-368.

35. Berk M, Dean O, Cotton SM, Gama CS, Kapczinski F, Fernandes BS, Kohlmann $\mathrm{K}$, Jeavons $\mathrm{S}$, Hewitt $\mathrm{K}$ : The efficacy of $\mathrm{N}$-acetylcysteine as an adjunctive treatment in bipolar depression: An open label trial. J Affect Disord 2011, 135(1-3):389-394.

36. Chan A, Paskavitz J, Remington R, Rasmussen S, Shea TB: Efficacy of a vitamin/nutriceutical formulation for early-stage Alzheimer's disease: a 1-year, open-label pilot study with an 16-month caregiver extension. Am J Alzheimers Dis Other Demen 2009, 23(6):571-585.

37. Ghanizadeh A, Derakhshan N, Berk M: N-acetylcysteine Versus Placebo for Treating Nail Biting, A Double Blind Randomized Placebo Controlled Clinical Trial. Anti-inflammatory \& anti-allergy agents in medicinal chemistry 2013, 12(3):223-228

38. Kortsalioudaki C, Taylor RM, Cheeseman P, Bansal S, Mieliâ€ Vergani G, Dhawan A: Safety and efficacy of Nâ€ acetylcysteine in children with nonâ€ acetaminophenâ€ induced acute liver failure. Liver Transp/2008, 14(1):25-30.

39. McCracken JT, McGough J, Shah B, Cronin P, Hong D, Aman MG, Arnold LE, Lindsay R, Nash P, Hollway J, et al: Risperidone in children with autism and serious behavioral problems. N Engl J Med 2002, 347(5):314-321.

40. Owen R, Sikich L, Marcus RN, Corey-Lisle P, Manos G, McQuade RD, Carson WH, Findling RL: Aripiprazole in the treatment of irritability in children and adolescents with autistic disorder. Pediatrics 2009, 124(6):1533-1540.

41. Lord C, Rutter M, Le Couteur A: Autism Diagnostic Interview-Revised: a revised version of a diagnostic interview for caregivers of individuals with possible pervasive developmental disorders. I Autism Dev Disord 1994, 24(5):659-685.

42. Akhondzadeh S, Fallah J, Mohammadi MR, Imani R, Mohammadi M, Salehi B, Ghanizadeh A, Raznahan M, Mohebbi-Rasa S, Rezazadeh SA, et al: Double-blind placebo-controlled trial of pentoxifylline added to risperidone: effects on aberrant behavior in children with autism. Prog Neuropsychopharmacol Biol Psychiatry 2010, 34(1):32-36.

43. Ghanizadeh A, Sahraeizadeh A, Berk M: A Head-to-Head Comparison of Aripiprazole and Risperidone for Safety and Treating Autistic Disorders, a Randomized Double Blind Clinical Trial. Child Psychiatry Hum Dev 2013 [Epub ahead of print].

44. Aman MG, Singh NN, Stewart AW, Field CJ: The aberrant behavior checklist: a behavior rating scale for the assessment of treatment effects. Am J Ment Defic 1985, 89(5):485-491.

45. Shao J, Zhong B: Last observation carry-forward and last observation analysis. Stat Med 2003, 22(15):2429-2441.

46. Ghanizadeh A, Derakhshan N: N-acetylcysteine for treatment of autism, a case report. J Res Med Sci 2012, 17(10):985-987.

47. Hardan AY, Fung LK, Libove RA, Obukhanych TV, Nair S, Herzenberg LA, Frazier TW, Tirouvanziam R: A randomized controlled pilot trial of oral $\mathrm{N}$-acetylcysteine in children with autism. Biol Psychiatry 2012, 71(11):956-961.

\section{Submit your next manuscript to BioMed Central and take full advantage of:}

- Convenient online submission

- Thorough peer review

- No space constraints or color figure charges

- Immediate publication on acceptance

- Inclusion in PubMed, CAS, Scopus and Google Scholar

- Research which is freely available for redistribution

Submit your manuscript at www.biomedcentral.com/submit 